\title{
Radiation-induced PEGylated Ethambutol Has Low Antimycobacterial Activity in Vitro
}

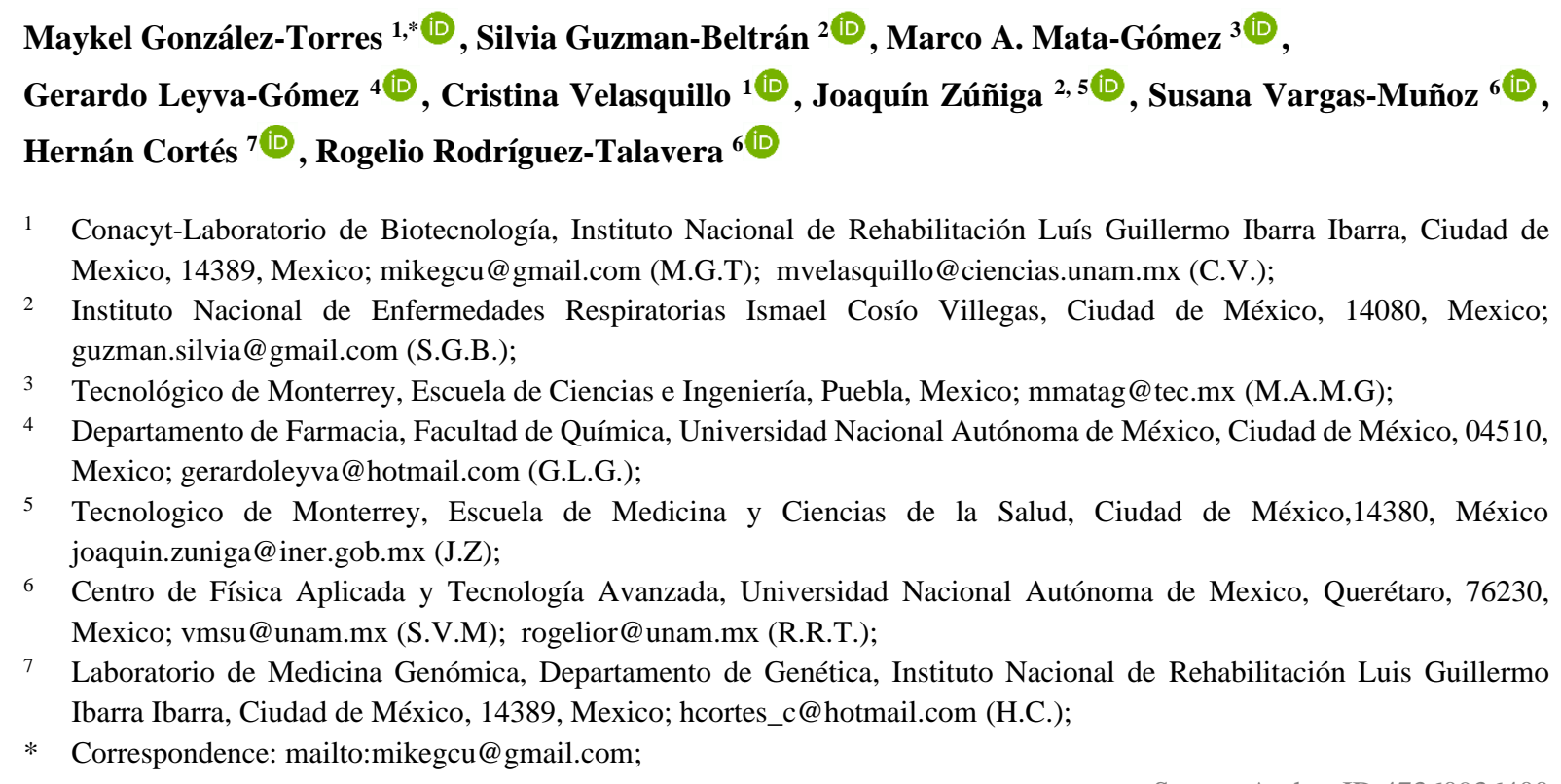

Received: 11.07.2020; Revised: 16.08.2020; Accepted: 18.08.2020; Published: 21.08.2020

Abstract: Tuberculosis is an airborne disease caused by Mycobacterium tuberculosis and remains one of the leading causes of death worldwide. The rise in multidrug-resistant strains has prompted the search for novel strategies to produce tuberculostatic agents. This research is aimed at developing a derivative of ethambutol by gamma radiation-induced polymerization with polyethylene glycol (PEG). The synthesis was verified by Raman spectroscopy and UV-Vis spectrometry. The results show that PEG can be chemically bonded to ethambutol by amine and alcohol groups. In in vitro biological evaluation, PEGylated and neat ethambutol showed similar cell viabilities, while the modified drug lowered bacterial growth inhibitory activity. A mechanism for the polymerization is proposed. The particle size increased for PEGylated drugs concerning the starting polyether. Despite the low antimycobacterial activity in vitro, the product seems to be a promising tool for the rapid screening of hydrolase activity.

Keywords: Antituberculotic; ethambutol; Prodrug; poly(ethylene glycol); Raman and UV-vis; PEGylation.

(C) 2020 by the authors. This article is an open-access article distributed under the terms and conditions of the Creative Commons Attribution (CC BY) license (https://creativecommons.org/licenses/by/4.0/).

\section{Introduction}

Tuberculosis (TB), caused by infection with Mycobacterium tuberculosis (MTB), is a highly prevalent and pandemic infectious disease that remains in the top 10 causes of death globally [1]. Ethambutol (EMB) is one of the first-line anti-tuberculosis agents commonly used against MTB [2]. Some of the advantages of this bacteriostatic agent are a) its synergy in combination with pyrazinamide, isoniazid, or rifampicin; and b) its ability to inhibit the arabinosyl transferase enzyme, which is key to increased permeability in the MTB cell wall to hinder its growth [3]. However, this front-line medication presents important drawbacks such 
as devastating side effects, including EMB-induced optic neuropathy (EON) and retinopathy [4]. MTB pathogens are also challenging to treat since antibiotics cannot be introduced into infected phagocytes. Hence, the challenge is to design a polymeric carrier for the development of a prodrug from ethambutol that can reduce toxicity and ensure adequate delivery of the antibiotic into cells. Radiation-induced PEGylation has proven to be an excellent pathway for the preparation of conjugates of small-molecular-weight drugs [5]. Polyethylene glycol (PEG) is ideal for the formulation of nanocomposites [6-11], hydrogels [12-17], nanogels [18-23], PEGylated phospholipid nanocarriers [24], PEGylated carbon nanotubes [25-29], PEGylated polybenzofulvene brushes [30] and PEGylated nano-delivery systems [31] due to its nontoxicity, low-immunogenicity, and good water solubility [32-34]. Recently, radiation-induced PEGylated cisplatin [5] and isoniazid [35] were reported. It is believed that the covalent bonding of PEG to EMB could produce a prodrug with reduced toxicity. It is mostly unknown whether the conjugate would be efficiently endocytosed by phagocytic-infiltrated cells. In the present research, we present, for the first time, the synthesis, characterization, and biological evaluation of ethambutol PEGylated using the simultaneous irradiation method. The mechanism of the direct reaction of PEG with EMB is proposed. Raman spectroscopy and ultraviolet-visible spectrophotometry (UV-Vis) were employed for the structural characterization of the novel pharmaceutical. The antimycobacterial activity and cell viability of the designed derivative are discussed.

\section{Materials and Methods}

\subsection{Materials.}

Ethambutol (2,2'-(1,2-ethanediyldiimino)bis-1-butanol dihydrochloride; EMB) and all PEGs were purchased from Sigma-Aldrich (MDL \# MFCD21364080, St Louis, MO, USA). Solutions of $12 \mathrm{mg} / \mathrm{mL}$ PEG ( $1 \mathrm{~g}$ of PEG added to $80 \mathrm{ml}$ of water) of 400, 1000, 3500, and $4000 \mathrm{Da}\left(\mathrm{M}_{\mathrm{w}}\right.$; polydispersity index of 0.025 ; 0.04 ; 0.034 ; and 0.047$)$, namely $\mathrm{G} 1, \mathrm{G} 2, \mathrm{G} 3$, and G4, respectively, were prepared in double-distilled water.

\subsection{Preparation of PEGylated EMB.}

Approximately $1 \mathrm{~g}$ EMB and $2 \mathrm{~mL}$ of each PEG solution $(12 \mathrm{mg} / \mathrm{mL})$ were mixed in Pyrex glass tubes and directly subjected to ${ }^{60} \mathrm{Co}-\gamma$-radiation in the air (Gamma Beam $651 \mathrm{PT}$, Nordion International) at doses of 5, 10, 15, 20, and $25 \mathrm{kGy}$ at a rate of approximately 1.5 $\mathrm{kGy} / \mathrm{h}$. The dose was measured using a Fricke dosimeter. As mentioned above, the radiation experiment was performed by the simultaneous irradiation method that consisted of the direct gamma irradiation of the solution composed of ethambutol and polyethylene glycol.

The EMB/PEG solutions (0.5 g (EMB)/ml(PEG solutions)) were degassed (before being irradiated) by freezing in liquid nitrogen for $15 \mathrm{~min}$ and subsequent thawing for two hours until two freeze-thaw cycles had been performed. The test samples were labeled as M3G1D1, M3G1D2, M3G1D3, M3G1D4, M3G1D5, M3G2D5, M3G3D5, and M3G4D5, where $\mathrm{M} 3$ was assigned to $\mathrm{EMB}$, and $\mathrm{D}$ and $\mathrm{G}$ represent the variations in dose and the molecular weight of PEG, i.e., M3G3D2 stands for PEGylated EMB with PEG of $3500 \mathrm{Da}$ at $10 \mathrm{kGy}$. Table 1 shows what the labels mean. 
Table 1. Labeling of the samples used for radiation-induced Pegylated EMB.

\begin{tabular}{|c|c|c|c|}
\hline samples & $\begin{array}{c}\text { molecular } \\
\text { weight of } \\
\text { PEG (Da) }\end{array}$ & $\begin{array}{c}\text { Dose } \\
(\mathbf{k G y})\end{array}$ & \\
\hline M3G1D1 & 400 & 5 & \\
\hline M3G1D2 & 400 & 10 & \\
\hline M3G1D3 & 400 & 15 & \\
\hline M3G1D4 & 400 & 20 & \\
\hline M3G1D5 & 400 & 25 & \\
\hline M3G2D5 & 1000 & 25 & \\
\hline M3G3D5 & 3500 & 25 & \\
\hline M3G4D5 & 4000 & 25 & \\
\hline M3G1D5 & 400 & 25 & PEG-EMB $(\mathrm{mg} / \mathrm{ml})$ \\
\hline M3G1D5P1 & 400 & 25 & 18 \\
\hline M3G1D5P2 & 400 & 25 & 25 \\
\hline M3G1D5P3 & 400 & 25 & 38 \\
\hline M3G1D5P4 & 400 & 25 & 50 \\
\hline M3G1D5P5 & 400 & 25 & 75 \\
\hline M3G1D5P6 & 400 & 25 & 83 \\
\hline M3G1D5P7 & 400 & 25 & 111 \\
\hline M3G1D5P8 & 400 & 25 & 120 \\
\hline
\end{tabular}

*M3 stands for EMB; for instance, M3G1D1 is equivalent to EMB-G1-D1. The concentration of PEGEMB ( $\mathrm{mg} / \mathrm{ml})$ refers to $\mathrm{mg}$ of M3G1D5 in $\mathrm{ml}$ of water. The dose is a measure of the rate at which EMB/ PEG samples are being exposed to a ${ }^{60} \mathrm{Co}-\gamma$-radiation source.

\subsection{Characterization of PEGylated EMB.}

\subsubsection{Spectroscopic characterization.}

Increasing concentrations of PEGylated EMB were screened by spectroscopy and spectrophotometry. The M3G1D5 samples stated to be $18 \mathrm{mg} / \mathrm{mL}$ (P1), $25 \mathrm{mg} / \mathrm{mL}$ (P2), 38 $\mathrm{mg} / \mathrm{mL}$ (P3), $50 \mathrm{mg} / \mathrm{mL}$ (P4), $75 \mathrm{mg} / \mathrm{mL}$ (P5), $83 \mathrm{mg} / \mathrm{mL}$ (P6), $111 \mathrm{mg} / \mathrm{mL}$ (P7), and 120 $\mathrm{mg} / \mathrm{mL}$ (P8) PEGylated EMB were labeled as M3G1D5P1, M3G1D5P2, M3G1D5P3, M3G1D5P4, M3G1D5P5, M3G1D5P6, M3G1D5P7, and M3G1D5P8, respectively (see Table 1). The experiments were conducted in triplicate to ensure reproducibility and accuracy.

Raman spectroscopy of all samples was accomplished at ambient temperature in a micro-Raman spectrometer (Bruker Senterra, model 910, MA, USA) equipped with a 785-nm laser light source. A drop of each sample was placed on a clean and flat brass plate to avoid interference. The UV-Vis spectra of the samples were measured using a microplate spectrophotometer (Multiskan GO, Thermo Fisher Scientific Inc., Waltham, MA, USA). A multimode wavelength scan at room temperature with linear shaking was used. For this experiment, solutions of roughly $6 \mathrm{mg} / \mathrm{ml}$ of EMB and PEG-EMB were used.

\subsubsection{Biological assessments.}

American Type Culture Collection (ATCC 25177, Rockville, MD, USA) Mycobacterium tuberculosis H37Ra was grown at $37^{\circ} \mathrm{C}$ in $7 \mathrm{H} 9$ broth (Difco, Detroit, MI, USA) supplemented with ADC (Beckton Dickinson, BD, San Jose, CA, USA) $0.2 \%$ (v/v) glycerol, and $0.05 \%(\mathrm{v} / \mathrm{v})$ Tween ${ }^{\circledR} 80$, or on solid Middlebrook $7 \mathrm{H} 10$ medium (Difco) supplemented with OADC (BD), 0.5\% (v/v) glycerol, and 0.05\% Tween 80 (Sigma-Aldrich, St. Louis, MO, USA).

The antimycobacterial activity was assayed in 96-well microplate. $100 \mu \mathrm{L}$ PEGylated and neat EMB solution were added at final concentrations ranging from 0.1 to $5 \mu \mathrm{g} / \mathrm{mL}$, and each well was inoculated with $100 \mu \mathrm{L}$ of logarithmic bacterial suspension containing 105 colony forming units (CFUs)/mL. The perimeter walls were filled with sterile, distilled water 
to prevent evaporation. The plates were incubated for seven days at $37^{\circ} \mathrm{C}$. Subsequently, the CFUs were counted. All bacteria suspension for each well were transferred into the first tube of $1.8 \mathrm{ml}$ of diluent ( $7 \mathrm{H} 9$ medium supplemented) and vortex. The dilution series was continued by using a $0.1 \mathrm{~mL}$ sample from the first tube to the second tube with $0.9 \mathrm{~mL}$ of diluent, and these dilutions were repeated six times more. Then $100 \mu \mathrm{L}$ of each dilution was plated in $7 \mathrm{H} 10$ medium supplemented for triplicate. The plates were incubated at $37^{\circ} \mathrm{C}$ for seven days.

After incubation, count plates from each series that contained 30 to 300 CFUs. We determined the mean $\mathrm{CFU} / \mathrm{mL}$ or $\mathrm{CFU}$ per each dilution and tested sample. Finally, the minimal inhibitory concentration (MIC) was calculated for each compound. The Minimum inhibitory concentrations (MICs) were defined as the lowest concentration of an antimicrobial that inhibits the visible growth of a microorganism after incubation time [36].

Cytotoxic testing was performed using the 3-(4,5-dimethylthiazol-2-yl)-2,5 diphenyltetrazolium bromide (MTT, Sigma-Aldrich) reduction assay to determine the number of viable THP1 cells in culture [37]. The human acute monocytic leukemia cell line, THP1, was acquired from the ATCC (TIB202). THP1 cells were grown in RPMI-1640 medium supplemented with $2 \mathrm{mM}$ L-glutamine, $10 \mathrm{mM}$ HEPES, $1 \mathrm{mM}$ sodium pyruvate (Lonza, CA, USA), $10 \%$ heat-inactivated fetal bovine serum (Hyclone ${ }^{\mathrm{TM}}$, Logan, USA), and $50 \mu \mathrm{M} 2-$ mercaptoethanol (Bio-Rad Laboratories, Berkeley, CA, USA).

$0.3 \times 10^{6}$ cells for each well were seeded in 48-well plates and differentiated into macrophages by exposure to $50 \mathrm{nM}$ phorbol 12-myristate 13-acetate (PMA, Sigma-Aldrich) solution for three days, as previously described [38].

The PEG-EMB (339-5420 $\mu \mathrm{g} / \mathrm{mL})$ was added to the cells, and the plates were incubated at $37^{\circ} \mathrm{C}$ under a $5 \% \mathrm{CO}_{2}$ atmosphere for $24 \mathrm{~h}$, followed by quantitation of cell viability. Subsequently, the plates were centrifuged to eliminate the treatment, fresh phenol red-free RPMI medium, and $30 \mu \mathrm{L}$ MTT $(5 \mathrm{mg} / \mathrm{mL})$ were immediately added, and the plates were incubated for a further $2 \mathrm{~h}$. Absorbance at $570 \mathrm{~nm}$ was measured using an HT Multimode microplate reader (Biotek, WA, USA).

The laser particle sizer ANALYSETTE 22 produced by Fritsch GmbH was an apparatus used in the preliminary determination of the particle size distribution of EMB and EMB-PEG (M3D1G1).

\section{Results and Discussion}

The Raman spectrum of neat ethambutol shows the typical bands at $3316 \mathrm{~cm}^{-1}(\mathrm{O}-\mathrm{H}$ stretching), 3100-2400 $\mathrm{cm}^{-1}$ (a combination of intramolecular H-bonded hydroxyl), $3316 \mathrm{~cm}^{-1}$ (amine stretching vibrations), and 1500-500 $\mathrm{cm}^{-1}$ (molecular fingerprint region) (Figure 1a). Similarly, the Raman spectrum for PEG displays the characteristic bands at $2873 \mathrm{~cm}^{-1}$ (stretching vibrations of the $\mathrm{CH}_{2}$ groups) and $1500-450 \mathrm{~cm}^{-1}$ (associated fingerprint region) (Figure 1b). All PEG signals disappeared from the PEGylated drug spectrum, except for the band around $1460 \mathrm{~cm}^{-1}$ (asymmetrical bending mode of the $\mathrm{CH}_{2}-\mathrm{CH}_{2}$ groups), suggesting a complete reaction of the polyether with EMB. The Raman spectrum of PEGylated ethambutol subjected to increasing doses is shown in Figure 1c. The most striking features observed in Figure 1 is the appearance of two new bands at $1897 \mathrm{~cm}^{-1}$ and $1627 \mathrm{~cm}^{-1}$, assigned to the possible formation of amide $\left(\mathrm{R}_{1} \mathrm{CONR}_{2}\right)$ and carbonyl $(\mathrm{C}=\mathrm{O})$ groups, respectively. This result is evidence of the formation of products 6 and 7 (hereafter), which are isomers. Comparison of the spectra of the novel conjugate and EMB also indicates slight variations in the PEG-EMB fingerprint, but a sharp modification by amine and hydroxyl groups. The prodrug obtained at 
increasing doses hinted at concentration dependency, while the increase in PEG molecular weights caused contrasting results between M3G1D5 and the rest of the samples (Figure 1d). However, there are no apparent differences between the Raman spectra of M3G2D5, M3G3D5, and M3G4D5 [39].
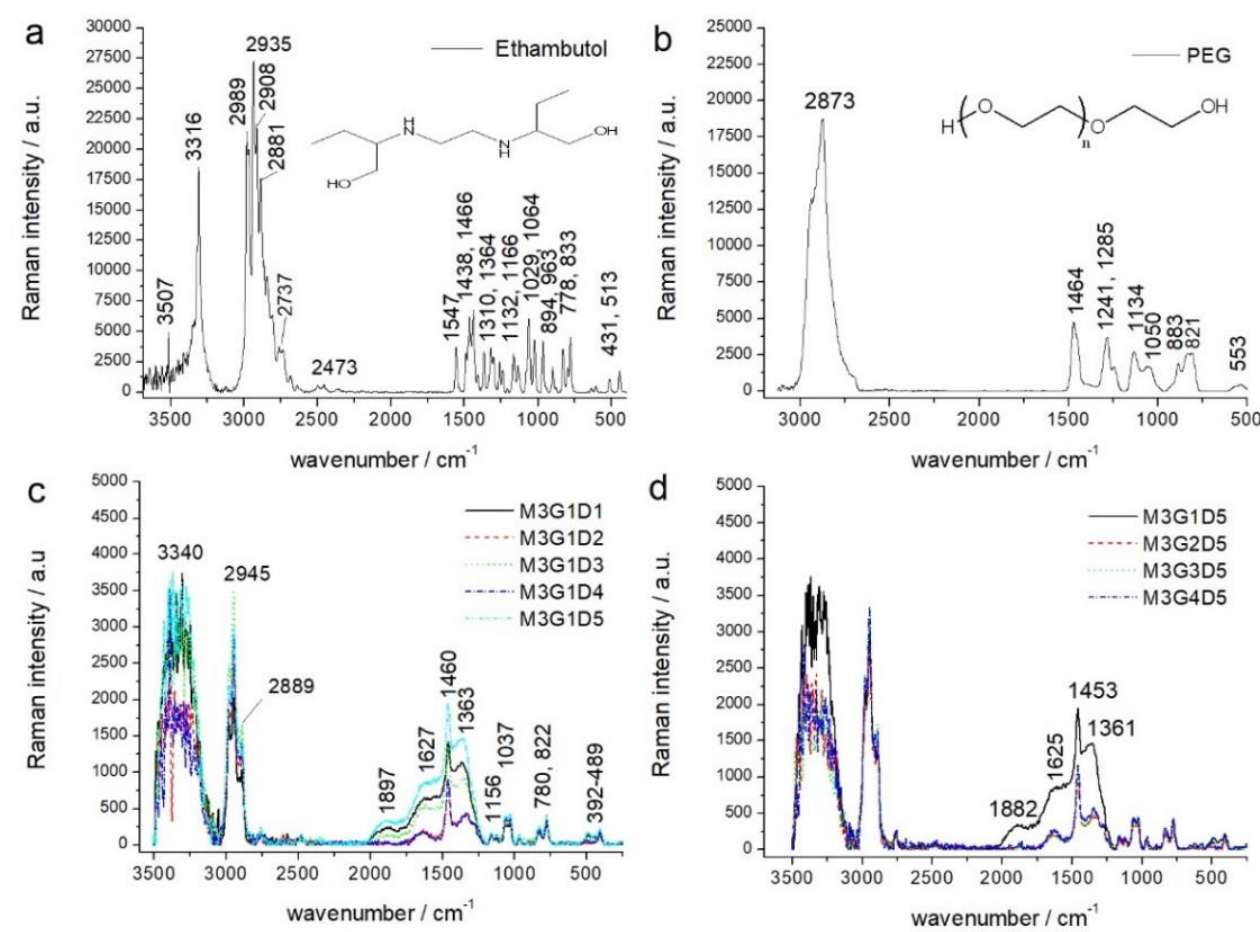

Figure 1. (a) Raman spectrum of ethambutol. (b) Raman spectrum of aqueous polyethylene glycol. (c) Raman spectrum of PEGylated ethambutol. (d) Effect of different doses on the synthesis of the PEG-EMB.
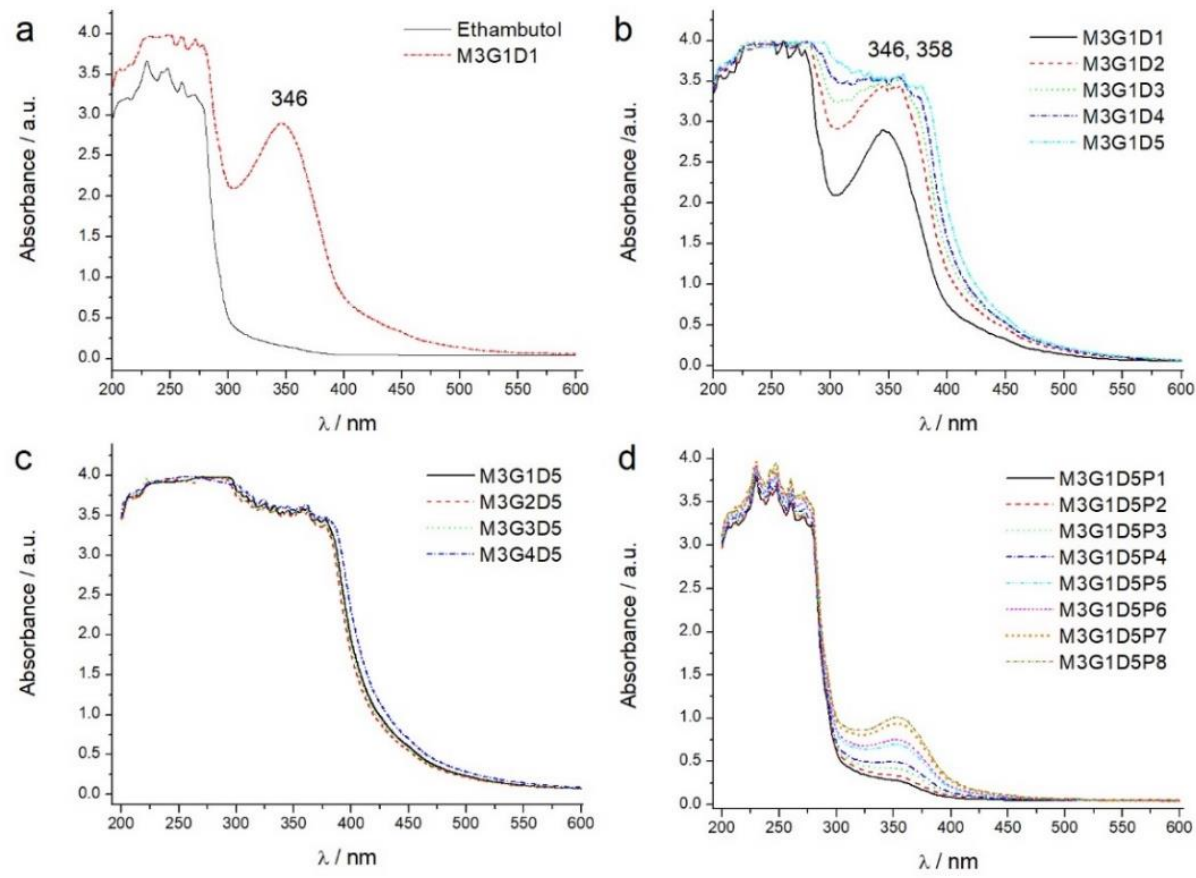

Figure 2. (a) UV-Vis absorption spectra of ethambutol and PEGylated ethambutol. (b) UV-Vis study of the effect of different doses on the PEG-EMB synthesis. (c) UV-Vis analysis of the effect of the use of increasing molecular weights of polyethylene glycol on the synthesis of PEG-g-EMB). (d) UV-Vis survey of the effect of the use of increasing concentrations of PEGylated EMB (M3G1D5). 
The UV-Vis absorption spectra of EMB and PEGylated ethambutol are shown in Figure 2a. EMB cannot be directly detected by calorimetry; thus, specific complexes such as copper or nickel or the addition of ninhydrin are used to detect the EMB chelate or primary/secondary amines. The presence of broadband in the range of 300-200 nm is consistent with a previous report using multivariate calibration for spectrophotometric analysis of ethambutol [40]. Noteworthy is the appearance of a new band at $346 \mathrm{~nm}$, which indicates the presence of a chromophore group, associated with the existence of carbonyl and amide groups. The experiment aimed to demonstrate the synthesis of the PEGylated drug [41]. It was also observed that the increase in concentration resulted in a bathochromic shift of the spectral band position from 346 to $358 \mathrm{~nm}$ (Figure 2b). The non-dependence of absorption on the molecular weight of PEG is exhibited in Figure 2c. The concentration dependence trend is displayed in Figure 2d; a higher concentration led to greater absorption bands.

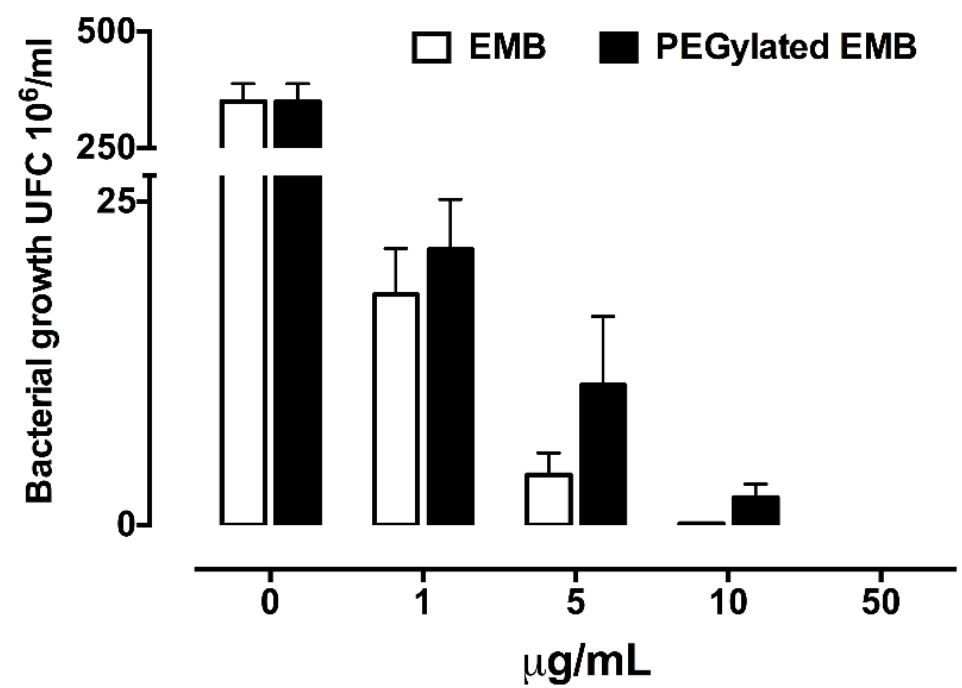

Figure 3. Effect of PEGylated ethambutol on bacterial growth. Bacteria were cultured in 7H9 Middlebrook medium supplemented with EMB or PEG-EMB for 7 days. Following incubation, CFUs were quantitated by counting the number of surviving bacteria for each compound concentration. Deviation and the statistical analyses were conducted using one-way analysis of variance (ANOVA). Data represent the mean $\pm S E(n=4)$. $* \mathrm{p}<0.05$ as compared with culture in the presence of EMB alone. PEG-EMB concentration in $\mu \mathrm{g} / \mathrm{mL}$ refers to EMB equivalents.

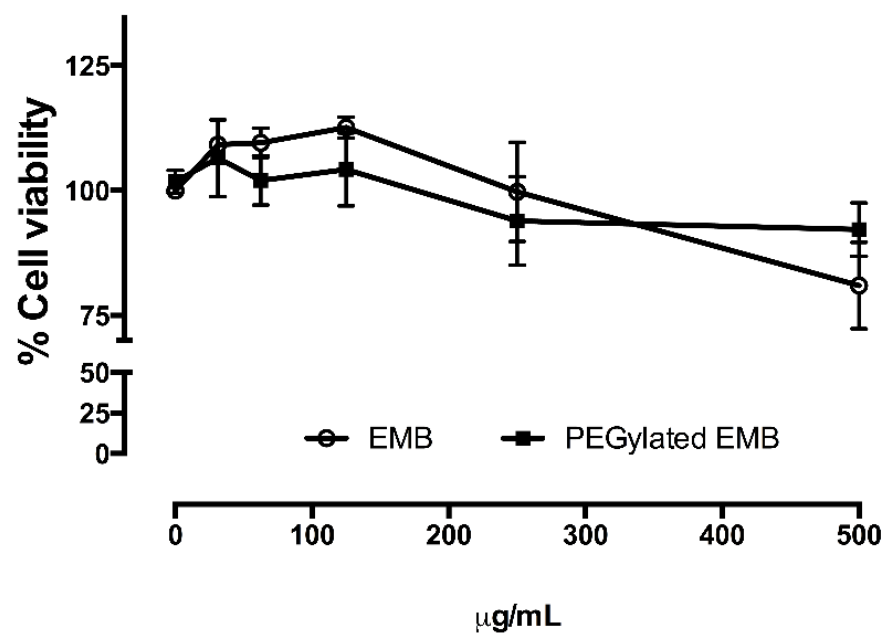

Figure 4. Effect of PEG-EMB on THP1 cell viability. The EMB or PEGylated EMB $(0-5420 \mu \mathrm{g} / \mathrm{mL}) \mathrm{was}$ added for $24 \mathrm{~h}$. PEG-EMB concentration in $\mu \mathrm{g} / \mathrm{mL}$ refers to EMB equivalents. Following exposure, fresh medium containing MTT was added for $2 \mathrm{~h}$. The number of viable cells is expressed as a percentage of MTT reduction concerning cells without treatment. 
The effect of PEGylated ethambutol on MTB H37Ra growth was evaluated (Figure 3). It exhibited a significantly lowered activity towards MTB as compared with EMB. Previous results are due to the activity of EMB is based on the inhibition of mycobacterial arabinofuranosyl transferases, which depends on the presence of the alcohol group [42]. The antimycobacterial activity in vitro lowered due to the modification of $-\mathrm{OH}$ functionality to an ester group (R1COO-OR2); however, the novel prodrug can be used for the evaluation of mycobacterial hydrolase activity because the ester group is susceptible to activation by serine hydrolase [43]. All synthesized conjugates displayed the same trend.

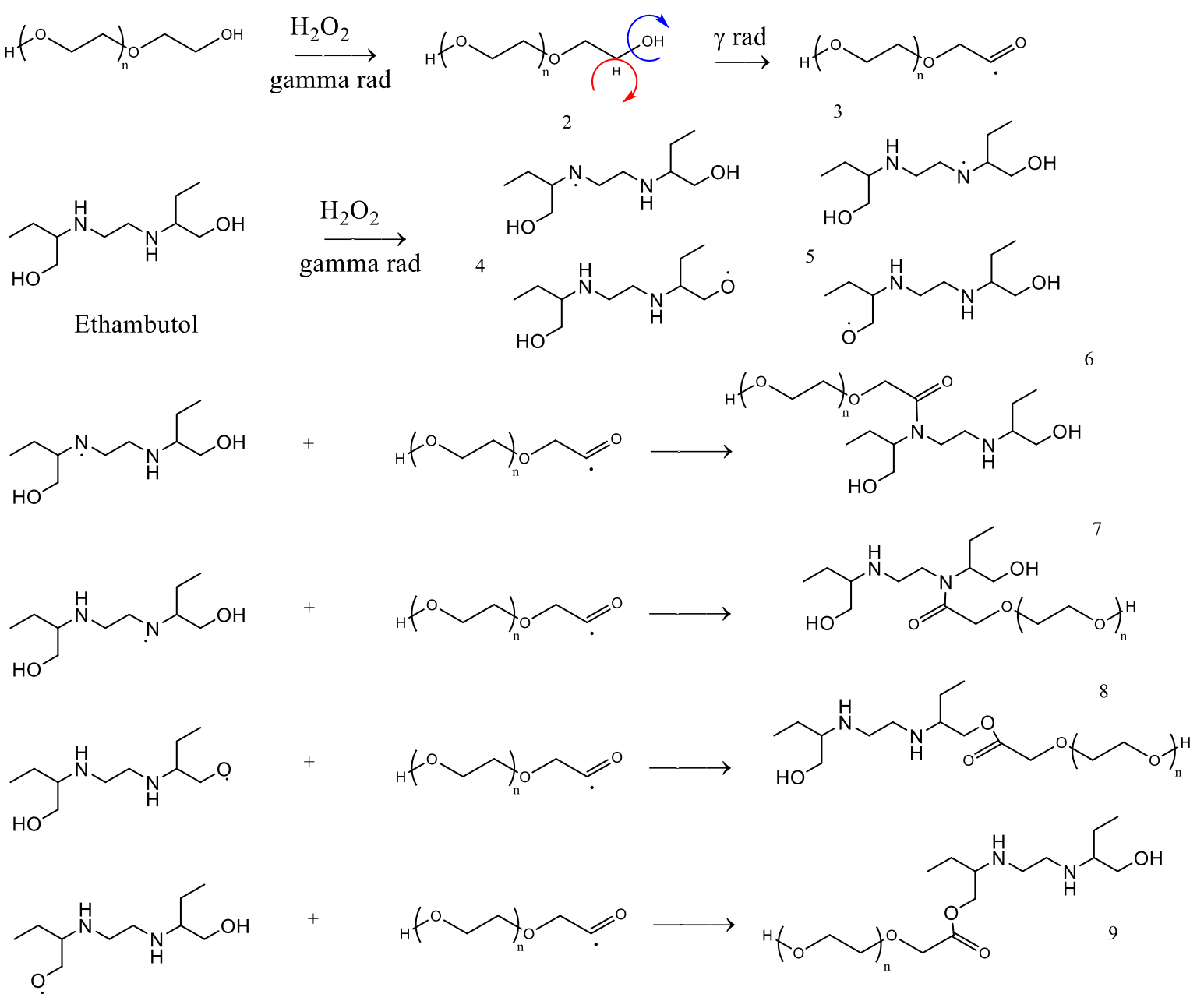

Figure 5. Proposed mechanism of gamma radiation-induced PEGylated ethambutol.

The effect of PEG-EMB on THP1 cell viability is shown in Figure 4. Similar behavior was seen for both samples concerning in vitro cytotoxicity. The PEGylated derivative scarcely contributed to cell viability. The main difference between the drugs is the mechanism of action of the ester-conjugate and its ability to achieve cell internalization following hydrolase activation.

Figure 5 shows the proposal for the synthesis mechanism of PEGylated ethambutol. In the first step (irradiation), primary radicals are formed. This step involves obtaining a PEG carbonyl radical (such as compound 1), four variants of EMB radicals (compounds 2-5), and the radiolysis of water. The absence of a monomer suggests the exclusion of the initiation and propagation steps.

Consequently, a termination reaction between the EMB radical and the PEG carbonyl radicals is more likely to occur (compounds 6-9). It is also possible to obtain EMB-PEG combined with compound 1 via a radical coupling reaction with the four EMB radical sites 
simultaneously. As a result, a complex mixture of PEG radicals of different molecular weight linked to several EMB radicals is obtained (including the ethambutol radical of carbon chains not shown in the mechanism proposal).

Figure 6 shows the particle size distribution of a) EMB and b) gamma radiationinduced PEGylated ethambutol. The results show that the diameter arithmetic means of EMB and EMB-PEG (M3G1D1) are $5.1 \pm 1.24 \mu \mathrm{m}$ and $20.7 \pm 0.49 \mu \mathrm{m}$, respectively. The particle size distribution of the samples also showed a normal distribution of PEGylated drugs, which supports the stability of the product. The increase in size is due to the PEGylation of the drug.
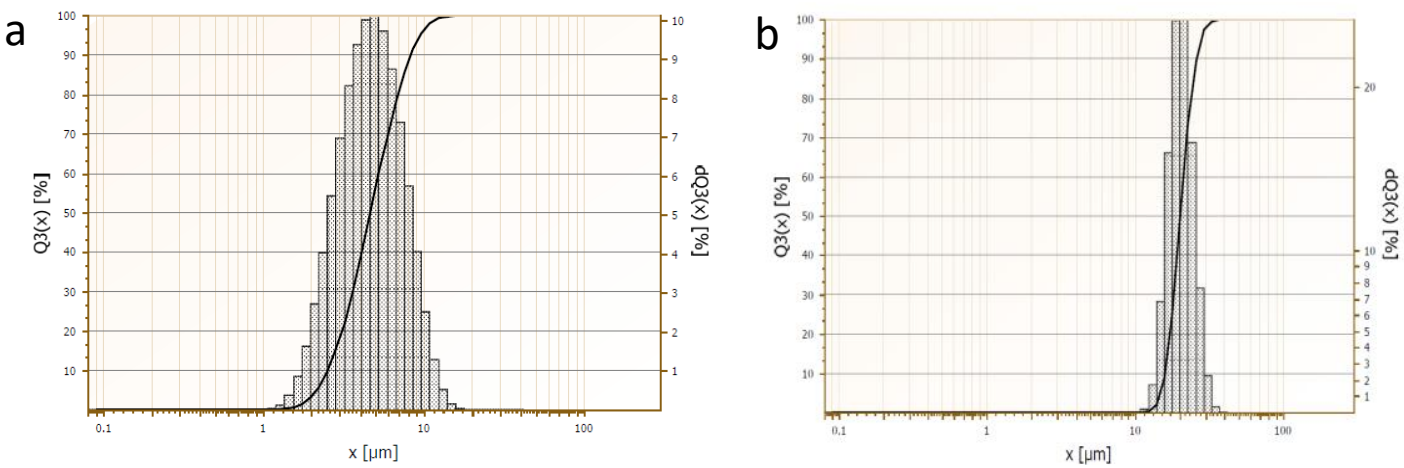

Figure 6. Particle size distribution of (a) EMB and (b) gamma radiation-induced PEGylated ethambutol.

\section{Conclusions}

A radiation-induced PEGylated ethambutol by direct linkage of PEG onto EMB was successfully prepared and structurally characterized by Raman and UV-Vis spectroscopy. Upon biological evaluation, EMB-PEG showed similar viability and a significantly lowered activity towards MTB as compared with EMB. The present research suggests that the advantages of preparing the ethambutol conjugate are an improvement in bioavailability, a decrease in toxicity, and an esterified EMB that could be useful for exploring the specificity of hydrolases as an activation mechanism towards understanding possible in vivo applications.

\section{Funding}

CONACyT-Mexico partially financially and supported this work through Cathedra's CONACyT 2020.

\section{Acknowledgments}

We acknowledge Carolina Muñoz, Miriam Guadalupe Bojorge, and Manuel Miranda for their help with Raman and UV/Vis measurements.

\section{Conflicts of Interest}

The authors declare no conflict of interest.

\section{References}

1. Fogel, N. Tuberculosis: A disease without boundaries. Tuberculosis 2015, 95, 527-531, https://doi.org/10.1016/j.tube.2015.05.017.

2. Caminero, J.A.; Sotgiu, G.; Zumla, A.; Migliori, G.B. Best drug treatment for multidrug-resistant and extensively drug-resistant tuberculosis. The Lancet Infectious Diseases 2010, 10, 621-629, https://doi.org/10.1016/S1473-3099(10)70139-0. 
3. Ahmad, M.I.; Ungphaiboon, S.; Srichana, T. The development of dimple-shaped chitosan carrier for ethambutol dihydrochloride dry powder inhaler. Drug Dev. Ind. Pharm. 2015, 41, 791-800, https://doi.org/10.3109/03639045.2014.903493.

4. Chamberlain, P.D.; Sadaka, A.; Berry, S.; Lee, A.G. Ethambutol optic neuropathy. Curr. Opin. Ophthalmol. 2017, 28, https://doi.org/10.1097/ICU.0000000000000416.

5. González Torres, M.; Cerna Cortez, J.; Balam Muñoz Soto, R.; Ríos Perez, A.; Pfeiffer, H.; Leyva Gómez, G.; Zúñiga Ramos, J.; Rivera, A.L. Synthesis of gamma radiation-induced PEGylated cisplatin for cancer treatment. RSC Advances 2018, 8, 34718-34725, https://doi.org/10.1039/C8RA06296J.

6. Mahmoud, G.A.; Ali, A.E.-H.; Raafat, A.I.; Badawy, N.A.; Elshahawy, M.F. Development of (acrylic acid/ polyethylene glycol)-zinc oxide mucoadhesive nanocomposites for buccal administration of propranolol HCl. Radiat. Phys. Chem. 2018, 147, 18-26, https://doi.org/10.1016/j.radphyschem.2018.01.020.

7. Tang, H.; Wang, M.; Meng, C.; Tao, W.; Wang, C.; Yu, H. Research on design, fabrication, and properties of $\mathrm{Fe} 2 \mathrm{O} 3 @ \mathrm{SiO} 2 / \mathrm{CD} / \mathrm{PEG} @ \mathrm{nSiO} 2$ nanocomposites. Mater. Lett. 2019, 235, 39-41, https://doi.org/10.1016/j.matlet.2018.09.149.

8. Qian, R.; Maiti, D.; Zhong, J.; Xiong, S. S.; Zhou, H.; Zhu, R.; Wan, J.; Yang, K. Multifunctional nanographene based nanocomposites for multimodal imaging guided combined radioisotope therapy and chemotherapy. Carbon . 2019, 149, 55-62, https://doi.org/10.1016/j.carbon.2019.04.046.

9. Ernest Ravindran, R.S.; Subha, V.; Ilangovan, R. Silver nanoparticles blended PEG/PVA nanocomposites synthesis and characterization for food packaging. Arabian Journal of Chemistry 2020, 13, 6056-6060, https://doi.org/10.1016/j.arabjc.2020.05.005.

10. Kupka, V.; Zhou, Q.; Ansari, F.; Tang, H.; Šlouf, M.; Vojtová, L.; Berglund, L.A.; Jančář, J. Well-dispersed polyurethane/cellulose nanocrystal nanocomposites synthesized by a solvent-free procedure in bulk. Polym. Compos. 2019, 40, E456-E465, https://doi.org/10.1002/pc.24748.

11. Jia, S.; Yu, D.; Wang, Z.; Zhang, X.; Chen, L.; Fu, L. Morphologies, crystallization, and mechanical properties of PLA-based nanocomposites: Synergistic effects of PEG/HNTs. J. Appl. Polym. Sci. 2019, 136, https://doi.org/10.1002/app.47385.

12. Park, J.-S.; Kim, H.-A.; Choi, J.-B.; Gwon, H.-J.; Shin, Y.-M.; Lim, Y.-M.; Khil, M.S.; Nho, Y.-C. Effects of annealing and the addition of PEG on the PVA based hydrogel by gamma ray. Radiat. Phys. Chem. 2012, 81, 857-860, https://doi.org/10.1016/j.radphyschem.2012.02.005.

13. Sautrot-Ba, P.; Razza, N.; Breloy, L.; Andaloussi, S.A.; Chiappone, A.; Sangermano, M.; Hélary, C.; Belbekhouche, S.; Coradin, T.; Versace, D.L. Photoinduced chitosan-PEG hydrogels with long-term antibacterial properties. Journal of Materials Chemistry B 2019, 7, 6526-6538, https://doi.org/10.1039/c9tb01170f.

14. Sharma, P.K.; Singh, Y. Glyoxylic Hydrazone Linkage-Based PEG Hydrogels for Covalent Entrapment and Controlled Delivery of Doxorubicin. Biomacromolecules 2019, 20, 2174-2184, https://doi.org/10.1021/acs.biomac.9b00020.

15. Nam, S.; Stowers, R.; Lou, J.; Xia, Y.; Chaudhuri, O. Varying PEG density to control stress relaxation in alginate-PEG hydrogels for 3D cell culture studies. Biomaterials 2019, 200, 15-24, https://doi.org/10.1016/j.biomaterials.2019.02.004.

16. Hunckler, M.D.; Medina, J.D.; Coronel, M.M.; Weaver, J.D.; Stabler, C.L.; García, A.J. Linkage Groups within Thiol-Ene Photoclickable PEG Hydrogels Control In Vivo Stability. Advanced Healthcare Materials 2019, 8, https://doi.org/10.1002/adhm.201900371.

17. Hammer, J.A.; Ruta, A.; West, J.L. Using Tools from Optogenetics to Create Light-Responsive Biomaterials: LOVTRAP-PEG Hydrogels for Dynamic Peptide Immobilization. Ann. Biomed. Eng. 2020, 48, 1885-1894, https://doi.org/10.1007/s10439-019-02407-w.

18. Eslami, P.; Rossi, F.; Fedeli, S. Hybrid Nanogels: Stealth and Biocompatible Structures for Drug Delivery Applications. Pharmaceutics 2019, 11, 71, https://doi.org/10.3390/pharmaceutics11020071.

19. Tian, Y.; Tian, R.; Chen, L.; Jin, R.; Feng, Y.; Bai, Y.; Chen, X. Redox-Responsive Nanogel with Intracellular Reconstruction and Programmable Drug Release for Targeted Tumor Therapy. Macromol. Rapid Commun. 2019, 40, 1800824, https://doi.org/10.1002/marc.201800824.

20. Osorno, L.L.; Maldonado, D.E.; Whitener, R.J.; Brandley, A.N.; Yiantsos, A.; Medina, J.D.R.; Byrne, M.E. Amphiphilic PLGA-PEG-PLGA triblock copolymer nanogels varying in gelation temperature and modulus for the extended and controlled release of hyaluronic acid. J. Appl. Polym. Sci. 2020, 137, 48678, https://doi.org/10.1002/app.48678.

21. Javanmardi, S.; Tamaddon, A.M.; Aghamaali, M.R.; Ghahramani, L.; Abolmaali, S.S. Redox-sensitive, PEG-shielded carboxymethyl PEI nanogels silencing MicroRNA-21, sensitizes resistant ovarian cancer cells to cisplatin. Asian Journal of Pharmaceutical Sciences 2020, 15, 69-82, https://doi.org/10.1016/j.ajps.2018.10.006.

22. Duan, X.; Yang, X.; Dai, C.; Tong, T.; Miao, C.; Zheng, J. One-pot synthesis of camptothecin-loaded glutathione-responsive PEGlyation nanogels as novel antitumor therapeutics. Materials Express 2019, 9, 757-763, https://doi.org/10.1166/mex.2019.1552.

23. Gu, J.; Clegg, J.R.; Heersema, L.A.; Peppas, N.A.; Smyth, H.D.C. Optimization of Cationic Nanogel PEGylation to Achieve Mammalian Cytocompatibility with Limited Loss of Gram-Negative Bactericidal 
Activity. Biomacromolecules 2020, 21, 1528-1538, https://doi.org/10.1021/acs.biomac.0c00081.

24. Muralidharan, P.; Mallory, E.; Malapit, M.; Hayes, D., Jr.; Mansour, H.M. Inhalable PEGylated Phospholipid Nanocarriers and PEGylated Therapeutics for Respiratory Delivery as Aerosolized Colloidal Dispersions and Dry Powder Inhalers. Pharmaceutics 2014, 6, 333-353, https://doi.org/10.3390/pharmaceutics6020333.

25. Ravelli, D.; Merli, D.; Quartarone, E.; Profumo, A.; Mustarelli, P.; Fagnoni, M. PEGylated carbon nanotubes: preparation, properties and applications. RSC Advances 2013, 3, 13569-13582, https://doi.org/10.1039/c3ra40852c.

26. Zhao, Y.; Yuan, Y.-C.; Bai, X.-L.; Liu, Y.-M.; Wu, G.-F.; Yang, F.-S.; Liao, X. Multi-mycotoxins analysis in liquid milk by UHPLC-Q-Exactive HRMS after magnetic solid-phase extraction based on PEGylated multi-walled carbon nanotubes. Food Chem. 2020, 305, 125429, https://doi.org/10.1016/j.foodchem.2019.125429.

27. Huang, H.; Liu, M.; Xu, D.; Mao, L.; Huang, Q.; Deng, F.; Tian, J.; Wen, Y.; Zhang, X.; Wei, Y. Facile fabrication of glycosylated and PEGylated carbon nanotubes through the combination of mussel inspired chemistry and surface-initiated ATRP. Materials Science and Engineering: C 2020, 106, 110157, https://doi.org/10.1016/j.msec.2019.110157.

28. Harsha, P.J.; Thotakura, N.; Kumar, M.; Sharma, S.; Mittal, A.; Khurana, R.K.; Singh, B.; Negi, P.; Raza, K. A novel PEGylated carbon nanotube conjugated mangiferin: An explorative nanomedicine for brain cancer cells. J. Drug Deliv. Sci. Technol. 2019, 53, 101186, https://doi.org/10.1016/j.jddst.2019.101186.

29. Mahaling, B.; Verma, M.; Mishra, G.; Chaudhuri, S.; Dutta, D.; Sivakumar, S. Fate of GdF3 nanoparticlesloaded PEGylated carbon capsules inside mice model: a step toward clinical application. Nanotoxicology 2020, 14, 577-594, https://doi.org/10.1080/17435390.2019.1708494.

30. Paolino, M.; Grisci, G.; Castriconi, F.; Reale, A.; Giuliani, G.; Donati, A.; Bonechi, C.; Giorgi, G.; Mendichi, R.; Piovani, D.; Boccia, A.C.; Canetti, M.; Samperi, F.; Dattilo, S.; Scialabba, C.; Licciardi, M.; Paccagnini, E.; Gentile, M.; Cappelli, A. Densely PEGylated Polybenzofulvene Brushes for Potential Applications in Drug Encapsulation. Pharmaceutics 2018, 10, 234, https://doi.org/10.3390/pharmaceutics 10040234.

31. Borran, A.A.; Aghanejad, A.; Farajollahi, A.; Barar, J.; Omidi, Y. Gold nanoparticles for radiosensitizing and imaging of cancer cells. Radiat. Phys. Chem. 2018, 152, 137-144, https://doi.org/10.1016/j.radphyschem.2018.08.010.

32. González, M.; Ceaglio, N.A.; de los Milagros Bürgi, M.; Etcheverrigaray, M.; Kratje, R.B.; Vaillard, S.E. Novel reactive PEG for amino group conjugation. RSC Advances 2015, 5, 14002-14009, https://doi.org/10.1039/c5ra00758e.

33. Xu, D.; Smolin, N.; Shaw, R.K.; Battey, S.R.; Tao, A.; Huang, Y.; Rahman, S.E.; Caylor, Matthew L. Molecular insights into the improved clinical performance of PEGylated interferon therapeutics: a molecular dynamics perspective. RSC Advances 2018, 8, 2315-2322, https://doi.org/10.1039/c7ra12480e.

34. Lonshakov, D.V.; Sheremet'ev, S.V.; Belosludtseva, E.M.; Korovkin, S.A.; Semchenko, A.V.; Katlinskij, A.V. Synthesis of 4-aminobenzoic acid esters of polyethylene glycol and their use for pegylation of therapeutic proteins. RSC Advances 2015, 5, 42903-42909, https://doi.org/10.1039/c5ra04950d.

35. González-Torres, M.; Guzmán-Beltrán, S.; Mata-Gómez, M.A.; González-Valdez, J.; Leyva-Gómez, G.; Melgarejo-Ramírez, Y.; Brostow, W.; Velasquillo, C.; Zúñiga-Ramos, J.; Rodríguez-Talavera, R. Synthesis, characterization, and in vitro evaluation of gamma radiation-induced PEGylated isoniazid. Electron. J. Biotechnol. 2019, 41, 81-87, https://doi.org/10.1016/j.ejbt.2019.07.005.

36. Byrne, S.T.; Denkin, S.M.; Gu, P.; Nuermberger, E.; Zhang, Y. Activity of ketoconazole against Mycobacterium tuberculosisin vitro and in the mouse model. J. Med. Microbiol. 2007, 56, 1047-1051, https://doi.org/10.1099/jmm.0.47058-0.

37. Foongladda, S.; Roengsanthia, D.; Arjrattanakool, W.; Chuchottaworn, C.; Chaiprasert, A.; Franzblau, S.G. Rapid and simple MTT method for rifampicin and isoniazid susceptibility testing of Mycobacterium tuberculosis. The international journal of tuberculosis and lung disease: the official journal of the International Union against Tuberculosis and Lung Disease 2002, 6, 1118-1122.

38. Stokes, R.W.; Doxsee, D. The Receptor-Mediated Uptake, Survival, Replication, and Drug Sensitivity of Mycobacterium tuberculosis within the Macrophage-like Cell Line THP-1: A Comparison with Human Monocyte-Derived Macrophages. Cell. Immunol. 1999, 197, 1-9, doi:https://doi.org/10.1006/cimm.1999.1554.

39. Chellini, P.R.; Mendes, T.O.; Franco, P.H.C.; Porto, B.L.S.; Tippavajhala, V.K.; César, I.C.; Oliveira, M.A.L.; Pianetti, G.A. Simultaneous determination of rifampicin, isoniazid, pyrazinamide and ethambutol in 4-FDC tablet by Raman spectroscopy associated to chemometric approach. Vib. Spectrosc 2017, 90, 1420, https://doi.org/10.1016/j.vibspec.2017.03.001.

40. Luiza, M.; Adriana, F.; Marcus, S.; Mariana, A.; Guilherme, S.; Ronei, P.; Marcone, O. Simultaneous analysis of first-line anti-tuberculosis drugs in tablets by UV spectrophotometry compared to capillary zone electrophoresis. Open Chemistry 2012, 10, 1808-1816, https://doi.org/10.2478/s11532-012-0102-6.

41. Salgado-Morán, G.; Ruiz-Nieto, S.; Gerli-Candia, L.; Flores-Holguín, N.; Favila-Pérez, A.; GlossmanMitnik, D. Computational nanochemistry study of the molecular structure and properties of ethambutol. $J$. Mol. Model. 2013, 19, 3507-3515, https://doi.org/10.1007/s00894-013-1884-y. 
42. Häusler, H.; Kawakami, R.P.; Mlaker, E.; Severn, W.B.; Stütz, A.E. Ethambutol analogues as potential antimycobacterial agents. Bioorg. Med. Chem. Lett. 2001, 11, 1679-1681, https://doi.org/10.1016/S0960894X(01)00258-X.

43. Larsen, E.M.; Stephens, D.C.; Clarke, N.H.; Johnson, R.J. Ester-prodrugs of ethambutol control its antibacterial activity and provide rapid screening for mycobacterial hydrolase activity. Bioorg. Med. Chem. Lett. 2017, 27, 4544-4547, https://doi.org/10.1016/j.bmcl.2017.08.057. 